\title{
El Plan de Inversiones para Europa
}

\author{
Juergen Foecking* \\ Comisión Europea
}

\begin{abstract}
Resumen
La crisis económica y financiera ha golpeado duramente a la Unión Europea. A pesar de la recuperación en los últimos años, los niveles de inversión continúan siendo débiles, puesto que la liquidez no se traduce en demanda real de financiación. Para revertir esta situación se ideó el Plan de Inversiones para Europa, que tras un primer año exitoso va a ser ampliado con el objetivo de continuar más allá de los tres años inicialmente previstos. El Plan de Inversiones invierte en sectores estratégicos prioritarios, como energías renovables, transportes e $I+D$. Para ello se sirve de tres pilares fundamentales. El primero consiste en un Fondo Europeo de Inversiones Estratégicas (FEIE) como catalizador de la financiación para la inversión. El segundo pilar radica en la mejora del marco de inversión, profundizando en el mercado único a través de la eliminación de barreras regulatorias. Por último, el Plan de Inversiones se complementa con varias iniciativas como el Centro Europeo de Asesoramiento para la Inversión y el Portal Europeo de Proyectos de Inversión, que actúa como enlace entre promotores e inversores.
\end{abstract}

Palabras clave: Plan de Inversiones para Europa, Unión Europea, sectores estratégicos.

Clasificación JEL: H54.

\begin{abstract}
The economic and financial crisis has hit the European Union heavily. Despite the recovery in recent years, investment levels remain weak, because liquidity does not reach the real economy. To improve this situation, the European institutions developed the Investment Plan for Europe, which after a successful first year will be extended in order to continue beyond the three years originally planned. The Investment Plan invests in strategic priority sectors, such as renewable energy, transport and $R \& D$. The Plan consists of three fundamental pillars. The first one is the European Fund for Strategic Investments (EFSI) as an impulse, mobilising funds for investment. The second pillar lies in the improvement of the investment framework, deepening the single market through the elimination of regulatory barriers for projects. Finally, the Investment Plan is reinforced with some initiatives such as the European Investment Advisory Hub, and the European Investment Project Portal, which acts as a liaison between developers and investors.
\end{abstract}

Keywords: Investment Plan for Europe, European Union, strategic sectors.

JEL classification: $H 54$.

\section{Introducción}

La crisis económica ha golpeado duramente a la Unión Europea. Desde su inicio en el año 2008, los niveles de crecimiento económico han sido bajos, el desempleo alto y se ha producido una notable disminución de las inversiones. Esto ha obligado

* Deseamos expresar nuestro agradecimiento a Gabriel Betancor Jiménez de Parga por su contribución en la elaboración y redacción de este artículo. 
a hacer enormes esfuerzos que en los últimos años hicieron mejorar la situación, asentándose la recuperación en todo el continente, incluso en países especialmente afectados por la crisis. Sin embargo, los niveles de inversión no parecían mejorar y continuaban siendo débiles, poniendo en riesgo la recuperación económica, el crecimiento, la creación de empleo y la competitividad. En 2013, por ejemplo, la inversión en la Unión Europea fue un 15 por 100 menor que durante el periodo precrisis, con una caída que en algunos Estados miembros alcanzaba el 60 por 100.

Estas carencias son el resultado de una falta de capacidad para asumir riesgos. Existe liquidez en el mercado pero esta no se traduce en demanda real de financiación por diversos motivos: por la falta de proyectos de inversión -debido a las barreras regulatorias-, por la baja confianza del inversor, la fragmentación de los mercados financieros y la volatilidad económica. Por eso se necesita un esfuerzo colectivo y coordinado a escala europea para volver a situar a Europa en la senda correcta. No hay una respuesta única y simple, ni en las instituciones europeas tenemos una varita mágica para crecer o una solución que lo resuelva todo.

Desde un primer momento se observó que no era ni posible ni aconsejable que la Unión Europea aportara toda la financiación requerida para recuperar la inversión. La elevada liquidez en el mercado, las limitaciones de los presupuestos públicos y los obstáculos a la inversión demandaban otro tipo de solución. Se debían atajar estos problemas para tener un éxito perceptible. Así, se ideó el Plan de Inversiones para Europa (Comisión Europea, 2014). Su éxito, después de tan solo un año, ha sido rotundo, como explicaba el Vicepresidente Katainen en un reciente discurso en el Plenario del Parlamento Europeo ${ }^{1}$. Tanto es así que el Plan se va a ampliar y reforzar para que pueda continuar más allá de los tres años inicialmente previstos (Comisión Europea, 2016a).

Este Plan de inversiones se creó a la luz de un hecho doloroso para nuestro continente: ninguna compañía tecnológica europea figuraba entre las quince más valiosas del planeta por cotización bursátil. En la Comisión Europea sabemos que esta brecha no se da por falta de ideas, porque nuestras empresas no sean tan creativas o innovadoras como las norteamericanas, por ejemplo, sino por factores externos que se lo ponen más difícil. Uno de los más importantes es, sin duda, el de la financiación. Con la crisis financiera y el daño sufrido en los balances, los proyectos de inversión de muchas empresas europeas no salieron adelante. Grandes ideas se quedaron en el tintero; la ilusión, ambición y ganas de prosperar no eran garantía suficiente como para se te concediera la financiación. El Plan de inversiones fue ideado para revertir esta situación, para invertir en sectores estratégicos prioritarios para Europa, poniendo el foco sobre la innovación. Contribuir a que aumente la competitividad y reforzar las infraestructuras para que ayuden a cohesionar más el mercado único son los objetivos clave de esta iniciativa.

El Plan de Inversión consta de tres pilares fundamentales que se complementan entre sí y que serán analizados a continuación en apartados separados.

1 https://ec.europa.eu/commission/2014-2019/katainen/announcements/speech-vice-president-katainen-investment-plan-europe-european-parliament-plenary-8-june-2016_en. 


\section{El primer pilar: Fondo Europeo de Inversiones Estratégicas como catalizador de la inversión privada}

La función principal del Fondo Europeo de Inversiones Estratégicas (FEIE) sería la de actuar como catalizador, movilizando la financiación para la inversión. Sus fondos provienen tanto de la Unión Europea como del Banco Europeo de Inversiones. Las instituciones comunitarias han aportado 16.000 millones de euros en forma de garantías, mientras que el BEI contribuye con otros 5.000 millones de euros. De esta forma se ha constituido el Fondo Europeo para Inversiones Estratégicas, con cuyos fondos esperamos movilizar más de 300.000 millones de euros en tres años. Esta meta no se alcanzaría exclusivamente con dinero público, este solo asciende a los 21.000 millones de euros que conforman el FEIE. Los cálculos realizados en las instituciones europeas indican que estos fondos serían suficientes para movilizar los 300.000 millones de euros restantes en forma de contribuciones privadas; esto es, un efecto multiplicador de $1: 15$. Y es que este dinero público se emplearía como garantía ante las primeras pérdidas por proyectos que, por su riesgo intrínseco, no saldrían adelante sin nuestra contribución e impulso. El Plan de inversiones no está concebido para financiar, ni mucho menos, íntegramente las inversiones propuestas.

En este sentido resulta imprescindible incidir en que estos fondos no están sometidos a ningún tipo de cuota, ni por país ni por sectores. Las instituciones no creamos los proyectos, son los promotores los que aportan las ideas que serán evaluadas en virtud de criterios de eficiencia económica, rentabilidad y viabilidad; son fondos impulsados por la demanda que apuestan por la innovación y por proyectos que, de no ser por la contribución del Plan, no saldría adelante dado su elevado riesgo. Así, especial atención se le otorgan a las inversiones a largo plazo en sectores considerados estratégicos, como pueden ser: las energías renovables, los transportes, el I+D o en infraestructuras sociales o digitales.

Otra cuestión es la posibilidad de que esta financiación se combine con fondos estructurales. Encontramos en la región francesa de Nord-Pas-de-Calais ${ }^{2}$ un buen ejemplo: allí se constituía una plataforma de inversiones, especialmente común en el ámbito digital. Esta tiene como objetivo juntar el mayor número posible de start-ups y pymes para que puedan acceder conjuntamente a la financiación que ofrece el Plan, los Fondos regionales, el capital privado y los Fondos estructurales. Una plataforma como la aquí mencionada supone un modelo que podríamos copiar en otros Estados miembros y regiones.

No podemos concluir que el FEIE está reservado para las grandes corporaciones; no nos olvidamos de que son las pequeñas y medianas empresas las que emplean a dos terceras partes de los asalariados de nuestro continente. Precisamente por ese motivo las pymes tienen garantizado como mínimo un 25 por 100 de los fondos, destinados a las más innovadoras, las que más dificultades de financiación encuentran. Ya en su primer año de vida el FEIE habría movilizado cerca de 100.000 millones de

\footnotetext{
${ }^{2}$ http://www.eib.org/projects/pipeline/2014/20140293.htm.
} 
euros, beneficiando a 141.800 pequeñas y medianas empresas de todo el continente ${ }^{3}$, buen ejemplo del apoyo que estamos prestando desde las instituciones europeas para que ninguna gran idea se quede en el tintero por dificultades de acceso al crédito. Queremos que nuestras pequeñas y medianas empresas crezcan, ganen tamaño y proyección internacional, que sean más competitivas e innovadoras. Solo entonces podrán situar a Europa en el lugar que se merece en los rankings.

El 80 por 100 de estos 100.000 millones de euros movilizados hasta ahora, en apenas un año, se obtendrían del sector privado, procediendo el 20 por 100 restante de consorcios público-privados. Estas cifras demuestran que Fondo está en pleno rendimiento. La demanda de fondos por parte de las pymes demuestra que existe una auténtica deficiencia del mercado, que el Fondo corrige. Hay liquidez de sobra pero no financiación de capital riesgo. Además, como consecuencia de las regulaciones bancarias introducidas después de la crisis financiera, los bancos no pueden correr tantos riesgos como antaño, motivo por el que el FEIE resulta realmente imprescindible. Pensando a largo plazo, en las instituciones europeas estamos trabajando y desarrollando la Unión de Mercados de Capitales Europea (Comisión Europea, 2016b). Mientras tanto, no obstante, la financiación inmediata de las pymes puede cubrirse mediante los fondos.

\section{El segundo pilar: mejorar el marco de inversión}

Mejorar el marco de inversión eliminando barreras regulatorias, promoviendo reformas estructurales a escala nacional y aumentando la calidad de la normativa es otro de los objetivos básicos del Plan de Inversiones para Europa. La Comisión Europea ha prestado especial atención en remover las barreras a la inversión más importantes, las existentes a nivel nacional. Estas se integraron en las Recomendaciones Específicas por país, incentivando y haciéndoles ver a los Estados miembros los beneficios que estas reformas estructurales le reportarán a la economía nacional y local.

A nivel europeo los esfuerzos en materia de eliminación de barreras regulatorias se han centrado en profundizar en el mercado interior. Estas reformas tienen el potencial de convertirse en la parte del Plan de Inversiones para Europa que más influya sobre el empleo. Algunas de las iniciativas más importantes incluyen: la creación de un Fondo de los Fondos, una manera más sencilla de que las pymes puedan encontrar financiación de capital-riesgo; bajar los requisitos de capital a aquellas empresas que inviertan en infraestructura a largo plazo; avanzar en la creación del Mercado Único Digital o del Mercado único de Energía; y, finalmente, facilitar la expansión de los proveedores de servicios a otros Estados miembros. Si de algo debemos estar seguros es que profundizando en el mercado único, dando visibilidad y asistencia técnica a los proyectos de inversión acabaremos con muchas de las trabas con que

\footnotetext{
${ }^{3}$ http://ec.europa.eu/priorities/sites/beta-political/files/investment_plan_booklet_en.pdf.
} 
se encuentra quien quiere invertir en Europa. Esto resulta vital, promoviendo la inversión para salir de la crisis, incentivando que las ideas rompedoras, los avances técnicos y los proyectos estratégicos cuenten con la financiación que requieran. Para conseguirlo, se procedería a la eliminación de todo tipo de obstáculos normativos no financieros, tanto a nivel europeo como en cada uno de los Estados miembros, especialmente en sectores clave del mercado único, como en los mercados de capitales, de energía y el digital.

\section{El tercer pilar: ¿cómo se consigue que esta financiación llegue a la economía real?}

Meta esencial del Plan de Inversiones para Europa, y su razón de ser, es que la financiación llegue a la economía real. Con ello desde las instituciones europeas queremos trasladar un importante mensaje: cualquier persona con ilusión, ganas de prosperar e ideas innovadoras puede contar con nuestro apoyo y, además, con una doble vía para pedir información y asistencia especializada. Una buena idea no puede quedarse en el tintero tampoco por la dificultad de los trámites, por no saber cómo acceder a las ayudas o desconocer sus criterios. Para atajar esta problemática ponemos a disposición, también de las pequeñas y medianas empresas, una solución doble: en primer lugar, un Centro Europeo de Asesoramiento para la Inversión ${ }^{4}$ que presta servicios de asesoría personalizada y asistencia técnica.

Pilar fundamental del Plan de Inversiones para Europa, este es un Centro en el que se puede encontrar la información necesaria sobre cómo acceder a la financiación ofrecida por el Plan. El vicepresidente Katainen, ante el Parlamento Europeo, arrojaba las siguientes cifras como prueba de su buen funcionamiento: el Centro Europeo de Asesoramiento ha recibido ya más de 100 solicitudes, la mayoría de empresas privadas, en busca de información sobre cómo beneficiarse de los fondos europeos, consejos o asistencia técnica para mejorar la calidad de los proyectos. Más importante, sin embargo, es la labor que presta ayudando a construir plataformas de inversión, posibilitando la financiación de proyectos más grandes a partir de inversiones, a priori, reducidas.

Contamos también para alcanzar este objetivo con el Portal Europeo de Proyectos de Inversión ${ }^{5}$. Este actúa como punto de enlace, un puente entre promotores e inversores de todo el mundo, diseñado con la ayuda del sector privado para hacerlo lo más pragmático y práctico posible. La idea originariamente vino del mensaje inequívoco de los bancos de inversión: hay capacidad, voluntad y predisposición a invertir en infraestructuras en Europa, pero resulta una tarea demasiado ardua encontrar proyectos buenos, adecuados. Precisamente para solucionar este problema ideamos el Portal Europeo de Proyectos de Inversión; un sitio abierto y transparente

\footnotetext{
4 http://www.eib.org/eiah/.

5 https://ec.europa.eu/eipp/desktop/es/index.html.
} 
al que los promotores podrán enviar sus proyectos y mejorar su visibilidad. Abierto recientemente, a principios de junio, esperamos que cuente con miles de proyectos en un futuro no muy lejano.

\section{El futuro del Plan de Inversiones para Europa: su prolongación y la inversión en terceros países}

Hasta la fecha, el Plan de Inversiones para Europa se ha centrado exclusivamente en nuestro continente y el mercado único europeo. Esta estrategia ha dado sus frutos por lo que en las instituciones europeas buscamos formas ampliar de sus horizontes, más allá de nuestras fronteras. Ello podría conseguirse mediante la creación de un nuevo fondo, similar al del Plan, centrado en fomentar las inversiones en terceros países y buscar oportunidades de negocio para nuestras empresas con las que, en última instancia, ayudar a mitigar las penosas situaciones que obligan a emigrar a muchas personas. Es indudable que las causas de las migraciones son mucho más complejas, que no se pueden resolver de la noche a la mañana, pero somos optimistas respecto de las oportunidades y enorme ayuda que pueden brindar estas iniciativas. Podemos empezar usando nuestros recursos destinados a la ayuda al desarrollo de forma más eficiente. Estas son ideas que aún se encuentran en fase embrionaria, aunque en la Comisión Europea esperamos poder implementarlas en un futuro no muy lejano.

Dado el éxito cosechado, la Comisión Europea ha presentado una nueva propuesta para extender la duración del Plan de Inversiones para Europa. La meta que perseguiría esta extensión seguiría siendo la de corregir las deficiencias del mercado, no tanto ampliar las capacidades, objetivos o la escala del Plan Eso sí, antes deberemos analizar sus logros y posibles debilidades. Uno de estas, de esos aspectos a mejorar, es el reparto de los fondos entre los Estados miembros. La explicación de que esta situación se esté dando en la actualidad, de que los recursos no se estén adjudicando equitativamente, es sencilla: algunas autoridades públicas no han promocionado tanto el Plan de Inversiones para Europa como era de esperar. Como sabemos, este no financia proyectos públicos. No obstante, los Ministerios y las Administraciones Públicas juegan un rol esencial a la hora de publicitar y dar a conocer este tipo de iniciativas que tanto pueden beneficiar a las empresas del sector privado. Las diferencias en este sentido, como decimos, son más que sustanciales. En cualquier caso, las representaciones con que cuentan tanto la Comisión como el Parlamento Europeo en cada uno de los Estados miembros están preparadas para atender a cualquier interesado, tanto a las Administraciones Públicas estatales, regionales o a los propios promotores privados. Además, existen oficinas nacionales del BEI. Tanto unas como otras llevan a cabo acciones frecuentes, como conferencias, seminarios y eventos de diverso tipo para dar a conocer el Plan.

Iniciativas como el Plan de Inversiones para Europa forman parte de la ambiciosa agenda que las instituciones europeas estamos llevando a cabo para impulsar el cre- 
cimiento económico, la creación de puestos de trabajo y asentar la tan sufrida recuperación en nuestro continente. En su primer año de vida este Plan habría movilizado ya más de 100.000 millones de euros; y esperamos seguir haciéndolo al menos otros dos años más, alcanzando los 300.000 millones. Es una financiación destinada a los proyectos más innovadores, los que crean un mayor valor añadido, con los que poder situar a Europa en el lugar que se merece. Nuestro continente no tiene un déficit de grandes ideas y de sueños; solo ha carecido de la financiación necesaria para hacerlos posibles. Hasta ahora.

\section{Referencias bibliográficas}

[1]COMISIÓN EUROPEA (2014). «Un Plan de Inversiones para Europa». Comunicación de la Comisión, COM (2014), 903 final, noviembre. Bruselas.

[2] COMISIÓN EUROPEA (2016a). «Europe investing again: Taking stock of the Investment Plan for Europe and next steps». Comunicación de la Comisión, COM (2016), 359 final, junio, Bruselas.

[3] COMISIÓN EUROPEA (2016b): «Capital Markets Union-Accelerating Reform». Comunicación de la Comisión, COM (2016), 601 final, septiembre, Bruselas. 